\title{
Descentralização urbana e expansão imobiliária em áreas ambientalmente vulneráveis de Campina Grande-PB
}

\author{
Urban decentralization and real estate expansion in environmentally vulnerable areas of Campina \\ Grande-PB
}

\author{
ARAÚJO' ${ }^{1}$, D. C.; MARQUES ${ }^{2}$, A. L.; MOURA ${ }^{3}$, D. C. \\ douglas.cavalcante_@hotmail.com
}

\begin{abstract}
Resumo
Campina Grande, no agreste paraibano, concebida como cidade de porte médio, expressa contradições contemporâneas urbanas e socioespacais através de uma reestruturação pautada na segregação, tendo neste fenômeno, os bairros planejados. Os bairros planejados chegaram ao Brasil por meio das cidades jardins, que se constituem em bairros planejados segundo o conceito inglês de garden city, e que oferecem aos condôminos amplas áreas verdes com praças, parques, intensa arborização em suas calçadas, além de um traçado urbano sustentável. Diante dessa discussão, esse trabalho utilizou uma metodologia pautada na fragilidade ambiental e enalteceu que esses empreendimentos estão em terrenos com declividade superior a 30\%, onde as moradias se encontram assentadas sob Neossolos Litólicos associados a Cambissolos rasos embasados tanto por granito como por gnaisse, cuja susceptibilidade à erosão deve ser considerada ao preparar o terreno com técnicas engenharia especificas. Dessa forma, diante das características fisiográficas e do púbico alvo, pode-se ressaltar estar ocorrendo expansão urbana e descentralização da cidade de Campina Grande por ações em massa de deslocamento das classes C e D para ambientes vulneráveis, que podem acarretar danos materiais e humanos.
\end{abstract}

Palavras-chaves: fragilidade ambiental, características fisiográficas, organização espacial.

\begin{abstract}
Campina Grande, in the Paraíba agreste, which was conceived as a medium-sized city, expresses contemporary urban and socio-pastoral contradictions through a restructuring based on segregation, having in this phenomenon, planned neighborhoods. The planned districts arrived in Brazil through the city gardens, which are in neighborhoods planned according to the English concept of garden city, and that offer condominiums ample green areas with squares, parks, intense afforestation on their sidewalks, as well as an urban layout sustainable development. In view of this discussion, this work used a methodology based on environmental fragility and praised that these projects are in lands with a slope of more than $30 \%$, where the dwellings are settled under Littoral Neosols associated with shallow Cambisols based on both granite and gneiss, whose susceptibility erosion should be considered when preparing the site with specific engineering techniques. Thus, in view of the physiographic and target pubic characteristics, it is possible to emphasize that urban expansion and decentralization of the city of Campina Grande are occurring due to the mass actions of the $\mathrm{C}$ and $\mathrm{D}$ classes displacement by the territorial domain, but in vulnerable environments that can material and human damages.
\end{abstract}

Keywords: environmental fragility, physiographic characteristics, spatial organization.

\section{INTRODUÇÃO}

Tendo como princípio básico a importância da habitação, a cidade passa a concernir seletividade, fazendo com que exista uma complexidade de bairros/ruas, cada qual com sua configuração, função econômica e também social. Habitar com qualidade em muitas cidades 
apresenta-se restrito a determinados sujeitos e padrões, onde a maioria da população economicamente desfavorecida não se encaixa, causando, entre outros, a formação de núcleos urbanos sob vulnerabilidades ambientais.

Este quadro está evidenciado em Campina Grande, no agreste paraibano. Concebida como cidade de porte médio, expressa bem as contradições contemporâneas urbanas e socioespacais através de uma reestruturação pautada na segregação (ARAÚJO, 2015).

Campina Grande exerce forte influência sobre as cidades próximas; portanto a busca por atendimentos e serviços especializados em saúde, educação e ensino técnico, serviços jurídicos e etc, trazem migrantes pendulares que contribuem com os congestionamentos dos espaços e da mobilidade, não muito diferente do que acontece em cidades maiores. Mas este não é um problema endêmico local e tem se expressado em todas as cidades médias à luz da dinâmica econômica e da modernização urbana (SPOSITO, 1991).

Segundo Santos e Silva Junior (2009), o sítio urbano de Campina Grande tem configurações diversificadas e a formação territorial de seus bairros é expressa de forma irregular e até mesmo caótica, fazendo do sítio urbano uma cidade carente de acessibilidade e altamente vulnerável as práticas de subversão urbana.

Diante de problemáticas estruturais urbanas e perante a ascensão social promovida pelos Governos Lula e Dilma, Campina Grande recebeu maciços investimentos imobiliários voltados principalmente ao público de baixa renda do Programa Minha Casa Minha Vida. Entre esses investimentos estão os chamados bairros planejados, localmente construídos em áreas desvalorizadas devido restrições ambientais, como a topografia.

Diante dessa discussão, esse trabalho busca correlacionar a reestruturação urbana e descentralização de Campina Grande aos bairros planejados, construídos em locais que apresentam potencias vulnerabilidades ambientais.

\section{REFERENCIAL TEÓRICO}

O desenvolvimento desenfreado das cidades brasileiras nas últimas décadas, motivado pelo crescimento econômico e aumento do poder de compra das classes sociais, principalmente C e D, demandou a incorporação de um novo ramo de empreendimentos, os bairros planejados ou latifúndios urbanos.

Os bairros planejados são mais do que projetos de incorporação ou loteamentos, são cidades dentro de uma cidade que chegam ao mercado com um projeto urbanístico de um bairro inteiro, 
com o desenho de ruas, acessos e iluminação, mas desenvolvido por empresas privadas (Exame, 2013).

Esse novo ramo imobiliário chegou ao Brasil por meio das cidades jardins, que se constituem em bairros planejados segundo o conceito inglês de garden city; e que oferecem aos condôminos amplas áreas verdes com praças, parques, arborização, além de um traçado urbano sustentável. Esse conceito é originário do Novo urbanismo, um movimento que surgiu nos Estados Unidos entre a década de 1980 e 1990 que defende o uso misto de espaços urbanos em contrapartida ao zoneamento, que privilegia a centralização de funções (Exame, 2013).

O mercado de bairros planejados vem despertando cada vez mais a atenção de grandes empresas como incorporadoras, construtoras, loteadoras e companhias de urbanismo financiadas pelos incentivos de políticas públicas, como o Programa Minha Casa Minha vida (FREITAS, 2010).

Essas espacialidades foram discutidas por Corrêa (1989), que ressalta que o espaço urbano está sendo modernizado por grandes grupos imobiliários que conferem identidade territorial a cada cama da estratificação social. Para Castells (2000), existe no meio urbano, as dinâmicas de descentralização e segregação residencial. O primeiro se caracteriza pela territorialização de grupos populacionais em um dado território, diferenciando este, por individualidades físicas e culturais. O segundo acontece como forma de reprodução social, controlador, que interfere de maneira direta na vida de toda integridade urbana, não somente como forma de domínio de uma categoria.

Nessa discussão, a configuração urbana ressalta o poder aquisitivo do grupo social que a adquire. Tais expressões são percebidas em Campina Grande, que devido o congestionamento urbano do centro, a periferia e a zona perurbana refletem a expansão de empreendimentos imobiliários diversos (ARAÚJO et al., 2016).

Entre esses empreendimentos estão os dois bairros planejados (1 e 2) objetos desse estudo, que apresentam um delineamento urbanístico em áreas sob potenciais vulnerabilidades ambientais.

Por vulnerabilidade ambiental entende-se a probabilidade de uma comunidade ou área geográfica ser afetada por uma ameaça ou risco potencial da ocorrência de um desastre devido grande densidade demográfica, alterações acentuadas do meio físico, ocupações de terrenos inadequados, impermeabilização excessiva, poluição do solo e da água, e etc (INDIRA, 2010).

Na ciência geográfica, de acordo com DESCHAMPS (2006) o termo está diretamente atrelado às probabilidades de ser afetado negativamente por um fenômeno geográfico e/ou climático. Assim, as zonas ou áreas e populações vulneráveis são aquelas que podem ser atingidas por algum evento geográfico, como terremoto, enchente, enxurrada e seca. Por sua estrutura geomorfológica ou por simples localização geográfica, determinadas áreas são mais propensas a experimentar tais eventos, ou seja, são áreas potencialmente vulneráveis. 


\section{METODOLOGIA}

\subsection{Localização e área de estudo}

O município de Campina Grande localiza-se no agreste do estado da Paraíba, no semiárido brasileiro (Figura 1).

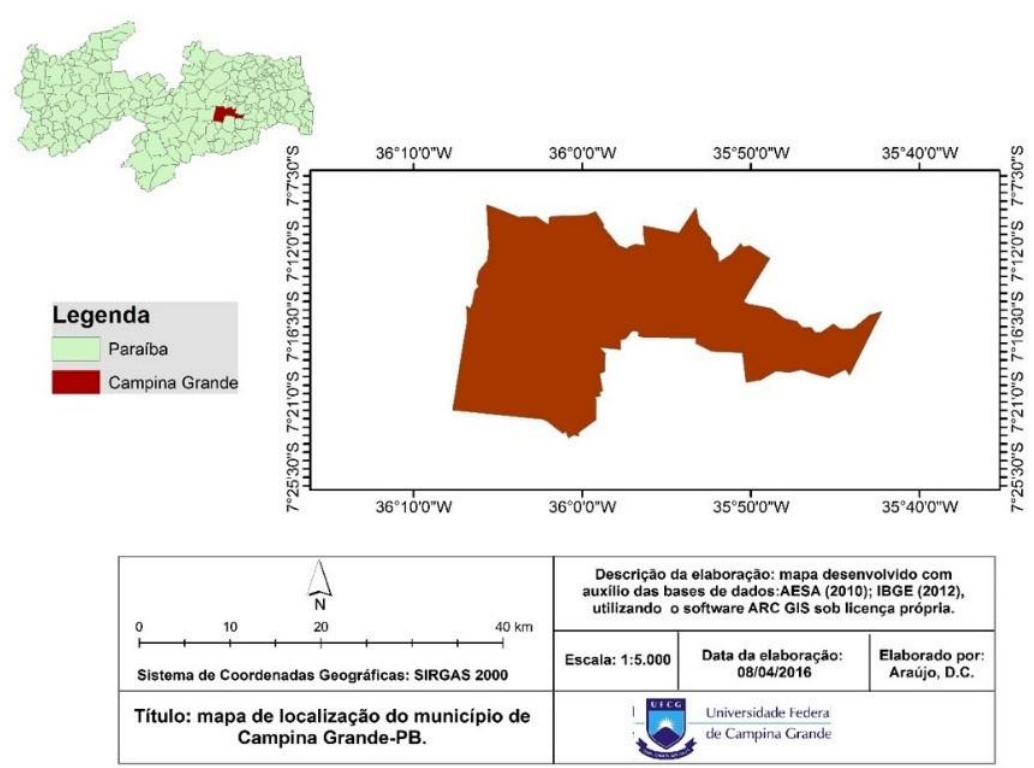

Figura 1. Localização geográfica do município de Campina Grande-PB. Fonte: Base de dados AESA (2010).

Campina Grande é considerada um dos principais polos industriais da Região Nordeste bem como principal polo tecnológico da América Latina segundo a revista americana Newsweek. Pertence a Região Geográfica Imediata de Campina Grande. Sua população é de 410.332 mil habitantes, sendo a segunda cidade mais populosa da Paraíba; sua região metropolitana é formada por dezenove municípios, e possui uma população estimada em 638. 017 mil habitantes (IBGE, 2017).

\subsection{Procedimentos metodológicos}

Esta pesquisa baseas-se em Sposito (2004), segundo a triangulação de métodos. Inicialmente fez-se necessária uma revisão de literatura referente ao tema proposto, onde se conseguiu obter a Legislação que regulamenta a cidade. Foram realizados também estudos de campo e levantamentos 
de dados junto à Secretaria de Desenvolvimento e Articulação Municipal e Secretaria Municipal de Planejamento Urbano.

Posteriormente se analisou aspectos fisiógrafos da cidade (geologia, tipos de solos, cobertura vegetal e declividade). Para isso foram cruzadas as shapefiles, no ArcGIS 10.5, de declividade (TOPODATA, 2018), uso da terra (Google Earth, 2018), geologia (AESA, 2012) e levantamento dos solos até o $3^{\circ}$ nível (SIBCS, 2013), conforme metodologia das classes de fragilidade ambiental proposta por Roos (1994), com escala espacial de 1:5.000.

\section{RESULTADOS E DISCUSSÃO}

Campina Grande apresenta diversos ramos de empreendimentos imobiliários (Figura 2) dos quais 15 se diferenciam em bairros planejados, loteamentos e condomínios de alto padrão verticais e horizontais. $90 \%$ destes empreendimentos estão correlacionados diretamente aos insumos do Programa Minha Casa Minha Vida do governo Federal nos vários estratos sociais do programa.

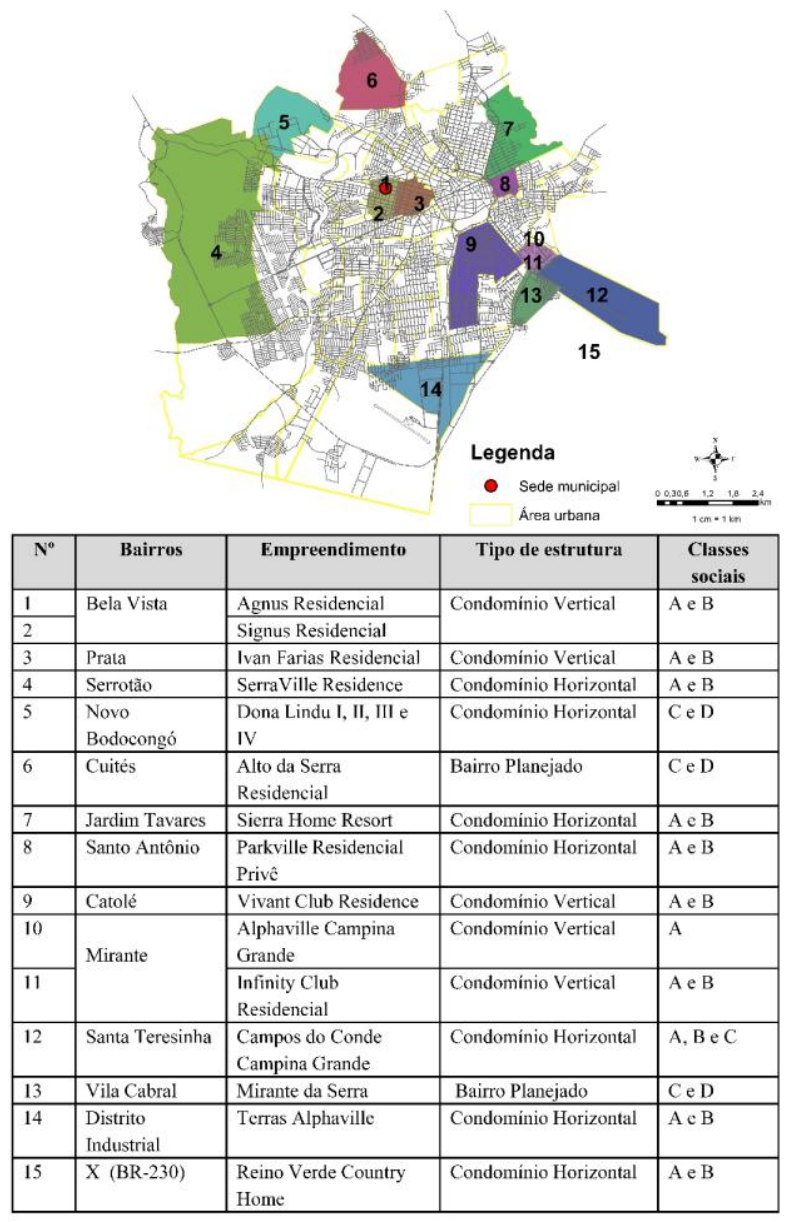

Figura 2. Mapa dos empreendimentos imobiliários de Campina Grande. Fonte: SEPLAN-CG (2018). 
Dentre os dois bairros planejados, o empreendimento em análise é o Alto da Serra, que localizam-se na zona periurbana dos Bairros dos Cuités (1). É um empreendimento que tem como foco as classes $\mathrm{C}$ e D, com imóveis de arquitetura padrão e estatuto condominial que variam de 100 a 145 mil reais.

Considerando a estabilidade do meio físico, ao classificar a cidade de Campina Grande tendo como intuito obter as classes de fragilidade ambiental, ambos bairros planejados localizam-se nas áreas de classes de fragilidade intermediária a muito alta (Figura 3).

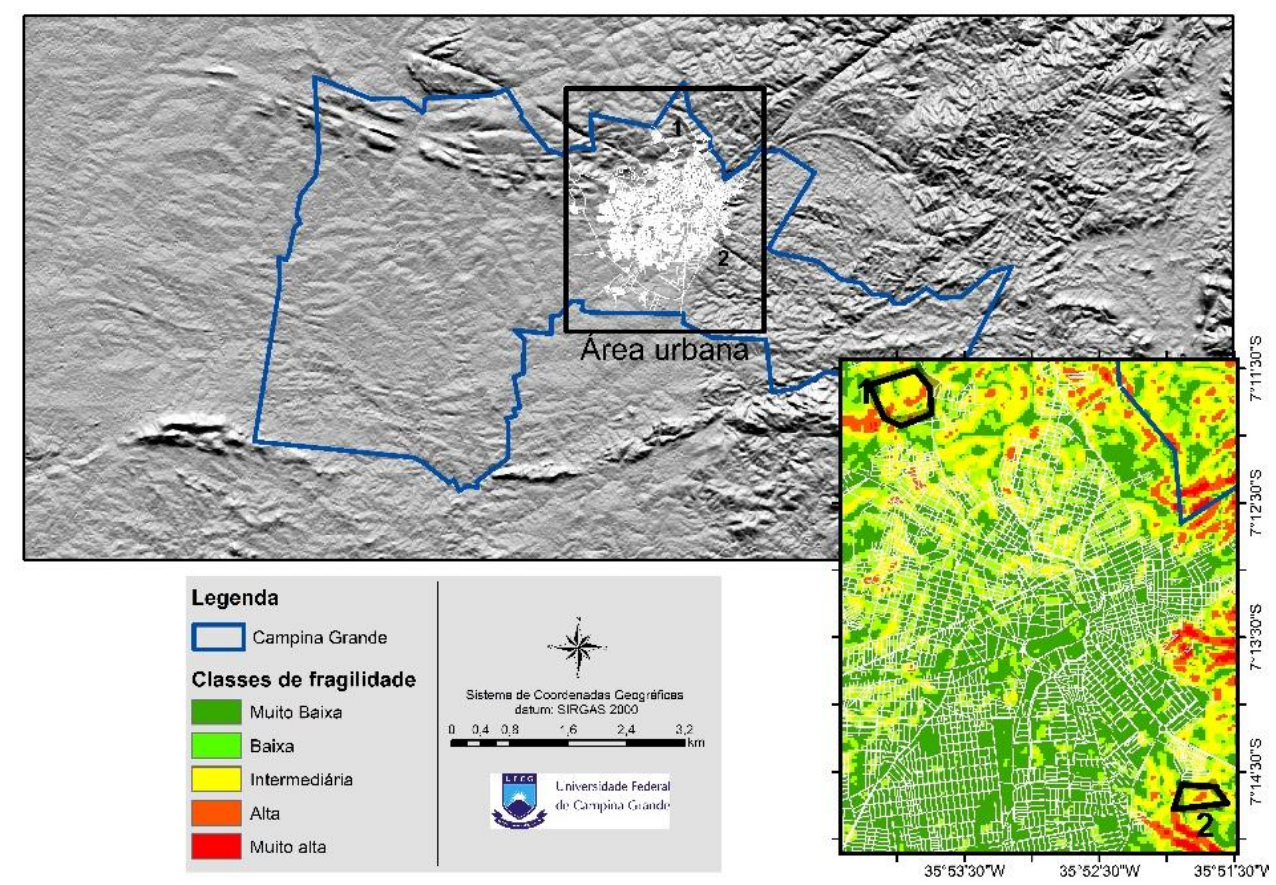

Figura 3. Mapa das classes de fragilidade dos empreendimentos. Fonte: os autores.

Estas classes reúnem declividade superior a $30 \%$, onde as moradias se encontram assentadas sob Neossolos Litólicos rasos associados a Cambissolos em coluviamento, embasados tanto por granito como por gnaisse, cuja susceptibilidade à erosão deve ser considerada ao preparar o terreno para construção.

$\mathrm{Na}$ (Figura 4) é possível observar, em um dos empreendimentos, o arranjo urbanístico das residências na posição de ombro do terreno (A) com declive alta e sem terraciamento e exposição de talude sem contenção (B). Tal ocupação é desconexa também perante a Lei do parcelamento do solo urbano (6.766/79). Ao ressaltar que não será permitido o parcelamento do solo: Art. $3^{\text {o: }}$ III - em terrenos com declividade igual ou superior a $30 \%$ (trinta por cento); IV - em terrenos onde as condições geológicas não aconselham a edificação (BRASIL, 1979). 


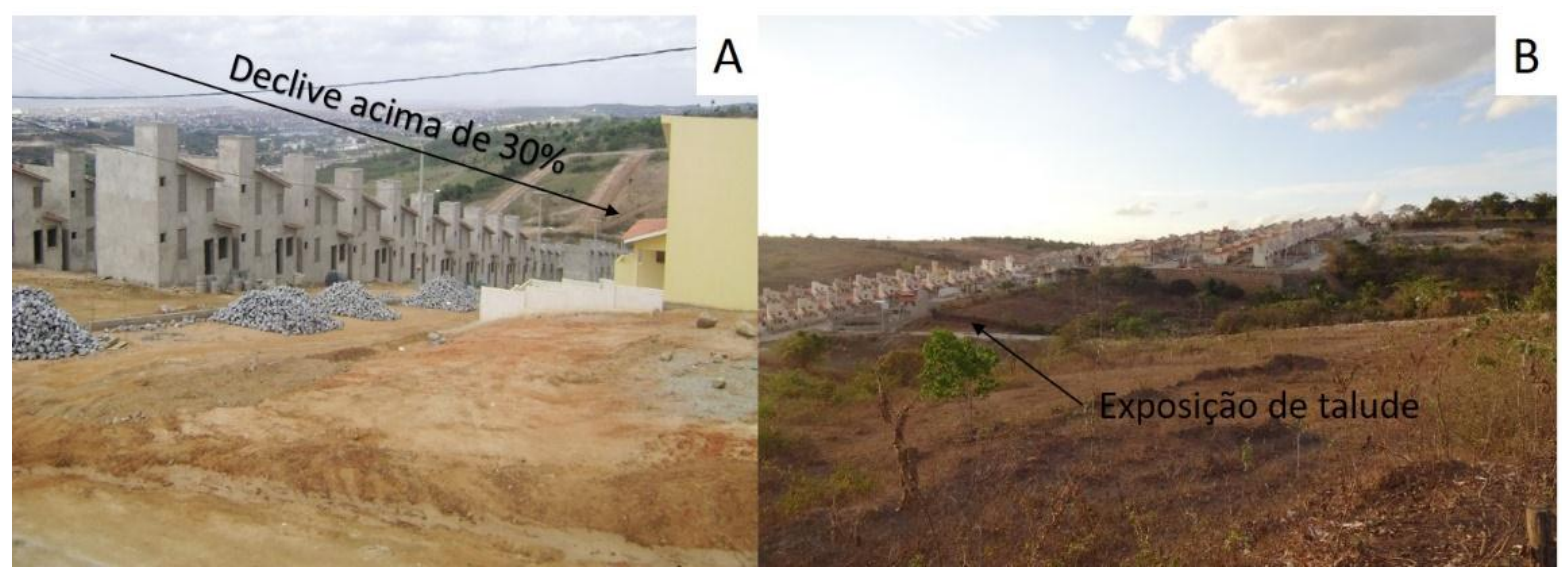

Figura 4. Delineamento urbanístico das residências do bairro planejado. Fonte: os autores.

Estas constatações estão corroboradas por Embrapa (2013) e Oliveira (2005). Segundo Embrapa (2013), os Neossolos Litólicos ocorrem diretamente sobre a rocha ou horizonte C. A pequena espessura do solo, com frequente ocorrência de cascalhos e fragmentos de rocha no seu perfil, origina grande susceptibilidade à erosão, mormente nas áreas de relevo acima de 30\%.

Para Oliveira (2005), os Cambissolos possuem um horizonte B incipiente, em estágio intermediário de intemperismo. Em geral não são muito profundos, apresentando teores relativamente elevados de minerais primários facilmente intemperizáveis. Devido ao seu estado incipiente, possuem de média a alta suscetibilidade à erosão principalmente em condições do relevo acima de $30 \%$.

\section{CONSIDERAÇÕES FINAIS}

Dessa forma, diante das características fisiográficas e do púbico alvo pode-se ressaltar que está ocorrendo expansão urbana e descentralização da cidade de Campina Grande; e especificamente as classes C e D para ambientes fisicamente vulneráveis, que podem acarretar danos materiais e humanos.

Através da instalação destes empreendimentos há formação de uma especulação imobiliária periférica a eles, que na maioria das vezes é realizada por camadas sociais de menor poder aquisitivo, devido os aspectos fisiográficos, gerando aglomerados urbanos desplanejados (favelização), que podem compor uma macrocefalia urbana.

Há de se pensar nos investimentos em serviços públicos (garantidos pela Constituição) para atender essa nova organização espacial, como coleta de lixo, postos de saúde, pavimentação de vias periféricas e iluminação, transporte público, educação e segurança. 
Destaca-se a importância do Minha Casa Minha Vida na descentralização de Campina Grande através do empreendimento Aluizio Campos que é um complexo industrial misto e imobiliário que tem como garantia o financiamento inicial de 4, 1 mil imóveis.

\section{REFERÊNCIAS}

ARAÚJO, D.C. A expansão dos condomínios habitacionais em Campina Grande e sua influência no processo de reestruturação urbana: a descentralização em debate. Universidade Federal de Campina Grande. Trabalho de Conclusão de Curso. 67p., 2015.

ARAUJO, D. C.; MARQUES, A. L.; OLIVEIRA, J. D.; NERI, U. D. B. Expansão de condomínios habitacionais no semiárido: reestruturação e segregação em debate. In: Congresso Internacional da Diversidade do Semiárido, 2017, Campina Grande-PB. Meio ambiente, 2016.

CASTELLS, M. A Questão urbana. Tradução de Arlene Caetano. Vol. 48. São Paulo: Paz e terra, 2000, 590p.

CORRÊA, R. L. O espaço urbano. São Paulo: Ática, 1989.

DESCHAMPS, M. V. Vulnerabilidade socioambiental nas regiões metropolitanas brasileiras. Brasília, Relatório de atividades do Observatório das Metrópoles. Convênio Ministério das Cidades/ Observatório das Metrópoles/Fase/Ipardes (2006).

EXAME. Bairros planejados (2013). Disponível em: https://exame.abril.com.br/negocios/construtoras-buscam-receita-com-bairros-planejados/ FREITAG, B. R. Teorias da cidade. 1. ed. Campinas: Papirus Editora, 2006. v. 1. 190p.

INDIRA. Significado de Vulnerabilidade. 2010. Disponível em: <http://www.dicionarioinformal.com.br/vulnerabilidade/>.

OLIVEIRA, J. B. Pedologia aplicada. Piracicaba: FEALQ, 2008. 592 p

ROSS, J. L. S. Análise Empírica da Fragilidade dos Ambientes Naturais e Antropizados. Revista do Departamento de Geografia. n 8, FFLCH-USP, São Paulo, 1994.

SANTOS, S. I. L.; SOUZA JUNIOR, X. S. S. Mapeamento da Violência Urbana em Campina Grande: Tendências e Desafios em Busca da Cidade Sustentável. 1ed.Rio de Janeiro: 2012, p. 167-186.

SPOSITO, M. E. B. Loteamentos fechados em cidades médias paulistas - Brasil. In: SPOSITO, M. E. B.; GOES, E. M. Espaços fechados e cidades: insegurança urbana e fragmentação socioespacial. 1a.. ed. São Paulo: Editora da Unesp, 2013. v. 1. 365p.

Recebido em: 13/04/2019

Aceito para publicação em: 25/05/2019 